\title{
ANTIQUITY
}

of the pot at B, can be measured. Alternatively, YA can be measured and added to the known $\mathrm{XY}$, if it is preferred not to move the pot. Whilst the pot and the device are in the position

\section{Saints of Wessex?}

This contribution is from Mrs Alice B. Kehoe who teaches in the Department of Sociology and Anthropology in Marquette University, Milwaukee, Wisconsin. Professor Renfrew has responded to our request to add his comments.

Colin Renfrew's (1973) view that neolithic Wessex was divided into chiefdoms is consistent with the Law of Uniformitarianism, but as Renfrew himself admits, allowing of greater refinement. An ethnographic model that may better fit the data is offered by Ernest Gellner in his study of Moroccan Berbers, Saints of the Atlas (1969).

Gellner describes the complex social and religious bricoleurs' delight through which an apparently anarchic people arrange their business and achieve a stable, economically successful cultural pattern. These Berbers perhaps ought not to be termed members of chiefdoms, lacking as they do 'pervasive inequality . . associated with permanent leadership' (Renfrew quoting Service and Sahlins), unless one considers the saintly mediators to fulfil the quoted criteria. Whether or not chiefdoms exist in the High Atlas of Morocco, Gellner's Berbers manage a society that matches Renfrew's Wessex data particularly at the two points at which, according to Renfrew (p. 556), the Wessex material fails to meet Service and Sahlins's definition of chiefdoms: the lack of ecological diversity and the lack of evidence for personal ranking.

A segmentary society, exemplified by the High Atlas Berbers, consists of 'social units ... at various levels of size, the larger incorporating the smaller as subparts' (Gellner, I969, 90). "The functions of maintaining cohesion, social control, some degree of "law and order" . . . can be performed with tolerable efficiency, simply by the "balancing" and "opposition" of constituent groups' (pp. 4I-2). 'Segmentation cannot be defined in terms of unilineal kinship, shown in FIG. $\mathbf{I} b$ it is also possible to measure the co-ordinates of points such as $\mathrm{D}$ (AC and $\mathrm{DC}$ ) or $\mathrm{F}$ ( $\mathrm{AE}$ and $\mathrm{EF}$ ). By plotting these and other points, the shape of the vessel can be recovered.

for the segmentation may be simply in territorial terms' (p. 48). 'Clan-loyalty . . . is sustained, roughly, by pasture rights, inheritance expectations, and rights to brides. Pasture rights are possibly the most important of these factors ... A tribesman knows that he may need the distant pastures in which he has a stake and which are guarded by his clan brethren, when, in due course, snow or drought, as the case may be, will render his nearby pasture useless' (p. 59).

'Berber society ... provides an exceptionally good specimen of the segmentary principle, of the maintenance of political order over extensive areas, large populations and diversified and complementary ecologies, without much in the way of a concentration of power, a centralized state. ... This relative segmentary purity . . is made possible by the saints [igurramen, 'marabouts', holy men]: these inegalitarian, stratified, pacific, "artificial" outsiders perform functions which enable the egalitarian, feudaddicted tribesmen to work their remarkably pure segmentary system' (p. 64). 'A visitor to the central High Atlas . . . could have observed [that] igurramen, possessors of baraka [divine blessing], are held worthy of reverence and with it of obedience; he would have noticed that baraka is highly concentrated, more so than its explanation in terms of descent [from the Prophet] would warrant, but in a way conducive to the effective concentration of influence; he would be assured by the igurramen that they appoint the annual secular chieftains (though he might notice that this is a misleading exaggeration), that they are the supreme court of the region, and that they communicate the unique Shra'a, Koranic legislation (though again the visitor might have his doubts about the accuracy of this claim [the igurramen are illiterate and actually uphold tribal tradition]). He would [notice] some features of this 


\section{NOTES AND NEWS}

"state", such as the lack of clear boundaries, the fact that it has more than one capital and centre of power, that its citizens may have multiple allegiances within and without its boundaries, sometimes depending on the season, and so forth' (p. 68).

What strikes the archaeologist is that the locus of governing (there is no government) for the High Atlas Berbers is the tomb of an agurram (singular of igurramen). Here reside the descendants of the revered man, including one or more who have inherited his baraka and serve as the living agurram or igurramen. An agurram 'is recognized ... when claiming and citing a holy geneaology ... has baraka. ... Stories of magical powers . . . will be told and believed of igurramen. Causal connection between objective blessing or disasters (good or bad harvests, cures or illnesses), and the acts, blessings and curses, of igurramen will be postulated and believed. ... An agurram will receive donations from people seeking blessing, which will enable him to be generous and hospitable.... An agurram will be revered and not be an object of aggression. . . . Being pacific, he will be able to carry out the tasks of an agurram' (p. 75). 'The services performed by igurramen are: The supervision of the election of chiefs ... mediation between groups in conflict ... acting as a court of appeal ... providing . . . for the main legal decision procedure, namely trial by collective oath, providing a sanctuary ... acting ... for those who are forced to seek a new place within the tribal structure ... providing leadership ... against outside agression ... providing . . . in connection with the complex spatio-temporal territorial boundaries which arise from transhumancy ... protection of travellers, of intertribal religious festivals and other activities ... being centres of information ... establishing and guaranteeing of such inter-tribal links as exist ... . working divine blessing, performing miracles, etc.' (p. 78). The most crucial service, in Gellner's estimation, is the maintenance of pasture rights through remembering traditional rights and mediating conflicts; through the latter function, the igurramen adjust tradition to current exigencies. These and all other functions depend ultimately upon the igurramen's gift of mediation between their clients and their sainted forefathers in the tombs, who in turn mediate with the Divine. Hence political life centres at the tombs.

The number and spacing of neolithic long barrows in Wessex seem congruent with a segmentary society dependent upon the mediation of saintly men inheriting holy power from revered forefathers buried in the tombs. In such a society, one would not find material inequality: no one accumulates or displays real wealth, for the igurramen receive only to redistribute hospitably. Ecological diversity of the type conceptualized by Service and Sahlins need not exist, for specialized production and trade are not parts of the model; the ecological differentiation Gellner mentions refers only to pastures sufficiently distant from one another that local calamities will not affect all the resources in the political region. Finally, the Wessex downs, though they may have held shifting agriculture in the Neolithic, must have been important grazing areas-according to Mr Humphrey Case grazing would have been especially important in the early Neolithic. The High Atlas kind of society could have become established in the second generation of settlement, at the death of the first agurram to migrate with the herders, precisely as described for the Berbers of the Ahansal region.

Areas other than the High Atlas have segmentary societies in which territorial rights and political co-operation are secured through the mediation of divinely blessed or ordained men serving at ancestral shrines. Roger Keesing (1970) discusses such societies in the Solomon Islands and in Africa, Though Keesing is focussing on kinship rather than territory or politics, his data fit with Gellner's and, I believe, Renfrew's Wessex material. The segmentary society governed by igurramen is a model more refined than Service and Sahlins's chiefdom, and in my opinion, closer to the Wessex Neolithic.

\section{Professor Colin Renfrew writes:}

Alice Kehoe's note raises a number of important issues. In the first place, she is right to 


\section{ANTIQUITY}

stress the underlying points of similarity between the example she quotes and early neolithic Wessex. Both may be viewed as segmentary societies, with a burial monument acting as the focal point for each territory. Such an arrangement, whether the focus be a tomb or a shrine, is very common in nonstratified societies, from the Tuamotu Islands (Ottino, 1967) to west Africa (Goody, 1973). The precise social mechanism which maintains the stability of the structure obviously differs from case to case, and the instance of the Berber agurram or holy man is interesting.

It is, however, important to distinguish between the different levels of an organization or hierarchy. Many chiefdoms comprise a mosaic of small, local territories each subordinate to the higher level jurisdiction exercised over the aggregate. My proposal (1973) was that the henge monuments of late neolithic Wessex indicate (and were the central places for) such larger polities, each including within its territory a score or so of the former long barrow territories.

I am not clear in the Berber case whether there is a social and spatial stratification of this kind. If there is, then the role of the agurram is in many ways analagous to that of a chief (in the sense of the word defined by Service), for there is certainly permanent inequality here, even if it is not expressed in material goods but in baraka. The role of the holy man in adjudicating over and regulating access to pasture land is clearly analagous to that of the chief in a situation of more marked ecological diversity. The services of the agurram, as quoted by Kehoe, undoubtedly include many that may be regarded as functions of a chief. And the existence also of purely secular chiefs creates no paradox: the separation of secular and religious powers was explicitly formulated in one of the classic Polynesian chiefdoms, where in Tonga the Tu'i Kanokupolu and the Tu'i Tonga had their own simultaneous rights and duties, although the latter was higher in status.

Different tendencies in chiefdom society may be simply, if crudely, expressed by distinguishing between 'group-oriented' and 'individualizing' chiefdoms (Renfrew, in press). The Berber case, if it can be regarded as a chiefdom at all, would fall like late neolithic Wessex, within the former category.

Archaeologists are only now beginning again to draw on the experience of contemporary and recent societies, which two generations ago proved so valuable a source of inspiration, and which has always lain at the root of much archaeological reasoning (Orme, 1973). A minority (I hope) of social anthropologists resents this renewed arachaeological incursion into what these, with heightened territorial awareness, regard as their own exclusive preserve. In the face of their essentially negative criticism we must simply work towards a more positive understanding of the structural features which the organizations of many societies hold in common. Spatial organization and sociospatial hierarchy indicate a first and obvious opportunity. Alice Kehoe has offered us a consideration of the archaeological implications of a specific social device for establishing and maintaining order, of a kind which has been missing for too long from the pages of ANTIQUITY. I hope that it heralds a much wider and freer discussion of these issues by archaeologists. Anthropology is too important to be left to the anthropologists alone.

GELLNER, E. 1969. Saints of the Atlas (London).

GOODY, J. I973. The social organization of the LoWiili (London, and edition).

KEESING, R. M. 1970. Shrines, ancestors, and cognatic descent: the Kwaio and Tallensi, American Anthropologist, LXXII, 755-75.

ORME, B. 1973. Archaeology and ethnography, in (ed.) C. Renfrew, The explanation of culture change: models in prehistory (London and Pittsburgh), $48 \mathrm{r}-92$.

otTino, P. 1967. Early 'Ati of the western Tuamotus, in (ed.) G. A. Highland, Polynesian culture history: essays in honor of Kenneth $P$. Emory (Honolulu), 45 $\mathrm{I}-82$.

RENFREW, C. I973. Monuments, mobilization and social organization in neolithic Wessex, in (ed.) C. Renfrew, The explanation of culture change: models in prehistory (Landon and Pittsburgh), 539-58.

in press. Beyond a subsistence economy: the evolution of social organization in prehistoric Europe, in (ed.) C. Moore, Reconstructing complex societies (American Schools of Oriental Research). 